\title{
Emerging Interconnects and Pb-free Materials for Advanced Electronic Packaging
}

\author{
ERIC COTTS $^{1}$ and BABAK ARFAEI ${ }^{1,2,3}$ \\ 1.-Physics Department, Binghamton University, Binghamton, NY 13902, USA. 2.-APL Labo- \\ ratory, Universal Instruments, Conklin, NY 13748, USA. 3.-e-mail: babak.arfaei@bingham- \\ ton.edu
}

The relentless drive for better performance in microelectronic devices has focused on increasing processor and signal transmission speeds within integrated circuits and increasing bandwidth, as well as enhancing the reliability of all aspects of the electronic package. ${ }^{1-6}$ While package designers approach apparent natural limits of processing and transmission speeds within the package, product applications continue to demand greater transmission speed and bandwidth between integrated circuits. This demand for increased bandwidth drives finer pitch solder interconnects. These design requirements are in addition to increasing reliability demands on interconnects; for instance, solder joints must handle increasing current densities, as their dimensions continue to decrease. Such demands for better performance of solder joints are being imposed at the same time as practitioners have been required to adapt to the removal of $\mathrm{Pb}$ from solder alloys. With all the design and assembly challenges of moving to $2.5 / 3 \mathrm{D}$ packaging structures, it has become imperative to improve our understanding of the materials science of $\mathrm{Pb}$-free solder joints. ${ }^{1,2,5}$

There are a number of difficulties associated with controlling the processing and microstructure of $\mathrm{Pb}$ free solder joints. These interconnects are generally fabricated with near-eutectic $\mathrm{SnAgCu}$, through a solidification process, thus limiting the precision of the control of a number of aspects of the interconnect. Heating the package to a temperature above the melting point of the solder in the reflow process results in a number of diffusive and solidification processes which must be carefully characterized and understood, in order to optimize the processing and performance of $\mathrm{Pb}$-free interconnects. The

Babak Arfaei is the guest editor for the Electronic Packaging \& Interconnection Materials Committee of the TMS Functional Materials Division, and coordinator of the topic Progress with Lead-Free Solders in this issue. thermal and mechanical properties of solder joints are directly dependent on these processes. Large changes in failure rates can result from small changes in time above the liquidus or in the cooling rate during solder joint formation. ${ }^{1,2,6}$ In addition, the stress state of Sn structures can result in an amazing but potentially deleterious physical phenomenon, the rapid growth of single Sn crystals (whiskers) out of solder, even under ambient conditions, that can cause electrical short circuits. Ways must be found to better control the microstructure of $\mathrm{Pb}$-free solder joints. We require a better understanding of factors in the assembly of fine pitch joints that affect reliability, and of failure mechanisms in drop/shock, vibration, thermal cycling and power cycling. We must optimize processing parameters such as surface finish, solder alloy, thermal history and we must develop new fluxes, thermal interface materials, die attach processes, conformal coatings and underfills in order to meet the demands on electronics packaging. Many of those topics were discussed during the Pb-Free Solders and Emerging Interconnect and Packaging Symposium at the TMS 2015 Annual Meeting in Orlando, Florida; three papers were chosen to illustrate these issues.

The first paper, by C. Gourlay et al., reviews the solidification of free-standing, near-eutectic $\mathrm{SnAgCu}$, and $\mathrm{Sn}-0.7 \mathrm{Cu}-0.05 \mathrm{Ni}$, solders. Changes in the solidification process that occur when the solder balls are attached to substrates commonly used by industry were examined. While the emphasis of this paper was on the formation of Sn grain morphology, the careful consideration of the influence of processes such as dissolution of the metallization, and both dendrite and pseudo eutectic formation, are also useful in the consideration of precipitate formation. The authors observed different Sn grain structures in $\mathrm{Sn}-\mathrm{Cu}-\mathrm{Ni}$ alloys, as compared to those observed in near-eutectic SnAgCu alloys. Effects of different metallizations, and their corresponding compounds 
with $\mathrm{Sn}$, on the nucleation of Sn were presented. Pt, $\mathrm{Pd}$ and Co metallizations were found to be the most effective at limiting undercooling. Studies such as this can contribute to the development of methods for controlling the microstructure of solder joints, one of the most complex issues to be addressed in the effort to increase the reliability of solder joints.

The second work, by R.J. Coyle et al., examines the relationship between solder joint reliability and solder composition in a range of accelerated thermal cycling regimes and two different dwell times. Twelve different $\mathrm{Pb}$-free solder alloys with different $\mathrm{Ag}$ concentrations and various microalloying additions were evaluated. While all $\mathrm{Pb}$-free solders in these tests performed better than $\mathrm{SnPb}$ solder joints, the effect of $\mathrm{Ag}$ on lifetime was less apparent for more severe testing conditions. As expected, lifetimes were significantly decreased by increasing the extremes of the temperature cycle from $0^{\circ} \mathrm{C}$ and $100^{\circ} \mathrm{C}$, to $-40^{\circ} \mathrm{C}$ and $125^{\circ} \mathrm{C}$. Increasing the dwell time from $10 \mathrm{~min}$ to $60 \mathrm{~min}$ also markedly decreased the lifetimes of all solder joints. The canonical correlation between $\mathrm{Ag}$ concentration and lifetime was clearly observed for ATC tests between $0^{\circ} \mathrm{C}$ and $100^{\circ} \mathrm{C}$, though this correlation was muted for the more severe test conditions. The results provided some indication that, for more severe conditions, the cost of the addition of $\mathrm{Ag}$ to $\mathrm{Pb}$-free solder may not be warranted.

The third work, by Eric Chason and Fei Pei, examines the formation of $\mathrm{Sn}$ whiskers in a $\mathrm{Sn}$ oxide/ $\mathrm{Sn} / \mathrm{Cu}_{6} \mathrm{Sn}_{5} / \mathrm{Si}$ planar sample configuration at different temperatures. The stress driving whisker growth arose from thermal mismatch and was quantified through measurements of the Si wafer curvature. Optical and electron microscopy provided measurements of the resulting hillock and whisker volume and density as a function of time. Thus, a quantitative assessment of the nucleation and growth rates of Sn whiskers was provided as a function of both applied stress and temperature. Activation energies for whisker nucleation were calculated on the basis of classical nucleation theory. Activation energies for whisker growth were calculated using a phenomenological model consistent with bulk and grain boundary diffusion. These observations lead to an informed discussion of the mechanisms of Sn whisker formation and plastic strain in such samples, and indicated the strong dependence of this complex phenomenon on sample microstructure.

We invite you to attend the Emerging Interconnect and $\mathrm{Pb}$-free Materials for Advanced Packaging Technology Symposium Committee Meeting and also the 12th Annual Lead-Free Solders and Interconnect Technology Workshop, that will be held in conjunction with the TMS 2016 Annual Meeting in February in Nashville, Tennessee.

The following papers being published under the topic of Progress with Lead-Free Solders provide excellent details and research on the subject. To download any of the papers, follow the url http:// link.springer.com/journal/11837/67/10/page/1 to the table of contents page for the October 2015 issue (vol. 67 no. 10).

- "Nucleation and Growth of Tin in Pb-free Solder Joints" C.M. Gourlay, S.A. Belyakov, Z.L. Ma, and J.W. Xian.

- "Thermal Fatigue Evaluation of Pb-Free Solder Joints: Results, Lessons Learned, and Future Trends" R.J. Coyle, K. Sweatman, and B. Arfaei.

- "Measuring the Stress-dependence of Nucleation and Growth Processes in Sn Whisker Formation" E. Chason and F. Pei.

\section{REFERENCES}

1. IEEE, in Proceedings of 65th Electronic Components and Technology Conference (ECTC) (Piscataway, 2015).

2. Surface Mount Technology Association, in Proceedings of SMTA International Conference (Edina, 2014).

3. Surface Mount Technology Association, in Proceedings of 11th Annual International Wafer-Level Packaging Conference (IWLPC) (Edina, 2014).

4. iNEMI, Roadmap (Herndon: International Electronics Manufacturing Initiative, 2015), p. 2015.

5. Binghamton University, in Presentations from the IEECCPMT Symposium on Electronics Packaging and 2.5D/3D (Binghamton, 8-9 Oct 2014.

6. IMAPS, in Proceedings of 47th International Microelectronics Assembly and Packaging Society (IMAPS) (Research Triangle Park, 2014). 